\title{
HIGHLIGHTS
}

DIABETES

\section{Pathogenesis of diabetes mellitus: does glutamate have a role?}

Glial glutamate transporter 1 (GLT1) is expressed in pancreatic $\beta$ cells and acts as a critical regulator of extracellular glutamate levels, which in turn promotes $\beta$-cell survival, report researchers in an article published in the Journal of Biological Chemistry.

Loss of $\beta$ cells is a key event in the pathogenesis of both type 1 and type 2 diabetes mellitus, but the causes are incompletely understood. Glutamate is an excitatory neurotransmitter of the central nervous system, but this factor also has a role in pancreatic islets, where it is secreted by a cells and acts as an intercellular signal mediator of hormone secretion.

The membranes of neuronal cells contain glutamate transporters that regulate extracellular concentrations of glutamate, which is essential to prevent neurotoxic effects. A glutamate transporter has also been identified previously in human pancreatic islet cells. Di Cairano and co-investigators wanted to shed light on the identity and physiological role of this transporter.

The researchers reveal that chronic exposure to glutamate induces cytotoxicity in $\beta$-cell lines and human islet $\beta$ cells but not $\alpha$ cells. Furthermore, in human $\beta$ cells, increased oxidative stress induced by chronic exposure to glutamate results in apoptosis and autophagy.

The investigators further show that in human islets, GLT1 is mainly expressed in the $\beta$ cells and is localized to the plasma membranes of these cells. In experiments to downregulate the expression of the GLT1 gene in $\beta$-cell lines, death of $\beta$ cells increased; by contrast, upregulation of expression promoted $\beta$-cell survival.

The investigators speculate that early in the development of both type 2 and type 1 diabetes mellitus, changes in the ratio of $\beta$ to a cells in favor of $\alpha$ cells disrupts

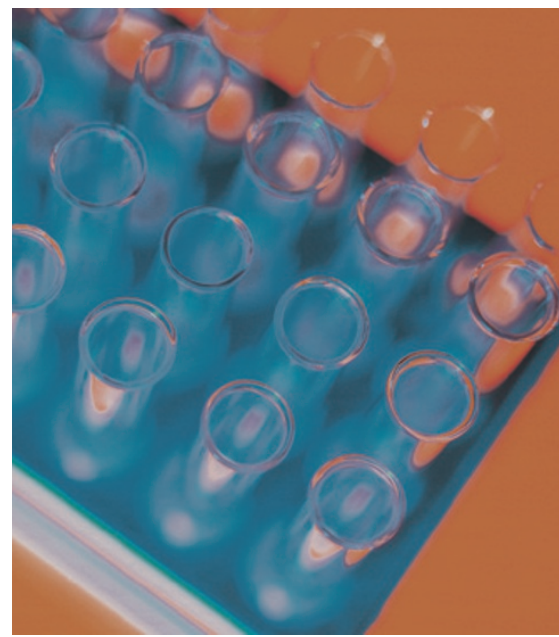

glutamate homeostasis in the islets. Increased concentrations of extracellular glutamate result, which perpetuate a vicious cycle of $\beta$-cell death and further rises in extracellular glutamate levels.

Carol Wilson

Original article Di Cairano, E. S. et al. The glial glutamate transporter 1 (GLT1) is expressed by pancreatic $\beta$-cells and prevents glutamate-induced $\beta$-cell death. J. Biol. Chem. doi:10.1074/jbc.M110.183517 